\title{
Filter mount system for the miniature indirect binocular ophthalmoscope
}

\author{
GEVES S. KENNY \\ San Diego, California, U.S.A.
}

Since the introduction of the indirect ophthalmoscope by Schepens (1947), the field of ophthalmology has witnessed an increasing sophistication in the instrument (Hovland, 응. Elzeneiny, and Schepens, I969; Weaver, 1970). The recently introduced miniatureog indirect binocular ophthalmoscope of Schultz and Crock (Crock, Galbraith, and Parel, I969) offers a lightweight spectacle-frame instrument with a portable rechargeable battery supply. This instrument has proved to have excellent optical qualities and to give suffi-o cient light for examination and surgery of the retina in consulting room and hospital. The value of the indirect ophthalmoscope in viewing the fundus fluorescein angiograms has been noted by Gass, Sever, Sparks, and Goren ( 1967 ). When it is used in combination with the fundus camera and contact lens slit-lamp examination, a thorough evaluation of $\vec{\bullet}$ the retinal status may be obtained. For the indirect ophthalmoscopic examination, either a cobalt blue or a Wratten $47 \mathrm{~A}$ filter is interposed in the instrument's light beam too permit the visualization of the fluorescein pattern.

Most of the commercially available indirect ophthalmoscopes offer, either by a swinginga mount or by a rotating dial, a means of selectively introducing the desired filter, but the $\frac{\mathbb{Q}}{\mathbb{Q}}$ Schultz-Crock Indirect Ophthalmoscope does not provide such a carrying system. Because $\overrightarrow{\vec{z}}$ of the acceptability of the Schultz-Crock instrument, a filter-carrying system has been 3 devised and is described below.

The 30 degree insert manufactured by the Carl Zeiss Company for their fundus camera provides an excellent holder (Fig. I). The desired Wratten gelatin filter is cut to a circular diameter to fit: tightly in the diaphragm base and the carrying clips are tightened. The cone end of the diaphragm 3 . slips easily over the circular lamp mount of the indirect ophthalmoscope (Fig. 2). The diaphragm 8 remains in position with head movements made during examination and the battery supply provides $₹$ sufficient illumination for viewing the fundus and the fluorescein distribution. This system has $\mathrm{O}$ worked well with cobalt blue and Wratten $47 \mathrm{~A}$ filters.
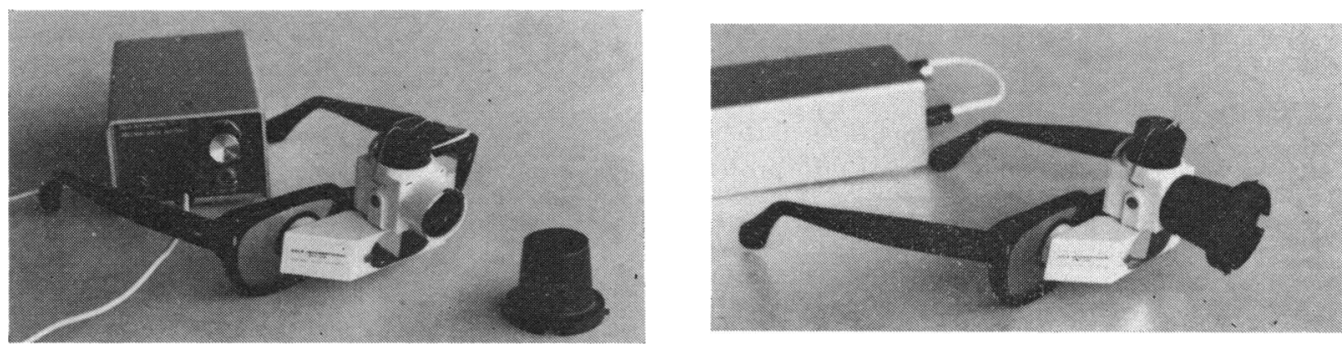

FIG. I $30^{\circ}$ diaphragm insert with miniature binocular indirect ophthalmoscope

FIG. 2 Diaphragm insert mounted on the indirect ophthalmoscope with filter positioned in base 
The fundus can be examined in red-free light by using the Wratten $5^{8}$ filter. This system has worked well in conjunction with office fluorescein angiography procedures and as an adjunct to photocoagulation treatment.

\section{Summary}

A filter mount system for the recently introduced Schultz-Crock Miniature Indirect Binocular Ophthalmoscope is presented. The diaphragm mount is easily obtained and insertion of the filter is simple. This modification extends the range of usefulness of this instrument to the area of fluorescein angiogram examination of the fundus.

\section{References}

Grock, G. W., GAlbraith, J. E. K., and PARel, J. M. (I969) Brit. 7. Ophthal., 53, 356

GASS, J. D. M., SEver, R. J., SPARks, D., and goren, J. (1967) Arch. Ophthal. (Chicago), 78, 455 HILl, D. W. (I968) Brit. F. Ophthal., 52, 28I

hovland, K. R., Elzeneiny, I. H., and schepens, C. L. (1969) Arch. Ophthal. (Chicago), 82, 466

schepens, C. L. (1947) Trans. Amer. Acad. Ophthal. Otolaryng., 51, 298

Weaver, J. H. (1970) Amer. J. Ophthal., 70, 430 